\title{
Reconceptualising the service paradox in engineering companies: is HR a missing link?
}

\begin{abstract}
Many global engineering organizations have gradually shifted away from the provision of tangible products towards the provision of high value combined product-service solutions. This business paradigm is purported to represent a key strategic opportunity for such firms, and has attracted the attention of practitioners, consultants and researchers. However, it has also been recognised that many firms fail to generate increased financial returns,, the socalled the 'service paradox'. Despite an emerging international research literature which alludes to cultural and human resource challenges, few studies have explicitly explored such issues from a human resource (HR) perspective. Informed by two in depth case studies of global engineering organizations in the United Kingdom, this article examines the HR challenges and reveals the complex realities of enacting product-service (PS) strategies in practice. It reveals that even where services have proved profitable, firms may still encounter various HR challenges, and struggle to fully exploit their service strategies. Addressing such challenges may represent a key enabler in delivering integrated product-services in organizations attempting to mesh distinctive engineering and service paradigms.
\end{abstract}

Keywords: Engineering industries, service, HRM, solutions, strategy

\section{Managerial relevance}

Given that one third of international manufacturers are now pursuing product-service business strategies, including many of the world's most high profile firms, this raises important issues for HRM. For management and practitioners, it is the creation of a supportive integrated service system which is likely to be key to achieving sustainable competitive advantage and differentiation in the 'solutions' marketplace. The engagement of HR professionals within the PS strategic agenda is likely to be key, yet the input of HR specialists and theorists are largely absent from the debate, dominated by marketing and operations management research. It is important to think through the implications of PS for HRM policy and practice, otherwise a mismatch may occur, potential leading to negative customer experience, even where services prove lucrative. An attempt to take into account HRM might involve, for example, increased emphasis upon external customer evaluations of the effectiveness of HRM as well as evaluations of performance from internal customers to encourage collaborative working. The advent of PS requires HR practitioners to adopt a more strategic role, engaging their expertise upfront to ensure HRM considerations are accounted for in the design and provision of service offerings. As long as HR remains neglected, people management issues will continue to represent a missing link in both the theory and practice of the product-service business phenomenon.. 


\section{Reconceptualising the service paradox in engineering companies: is HR a missing link?}

\section{INTRODUCTION}

Many high profile global engineering organizations traditionally associated with manufacturing have been deriving an increasing proportion of their total revenues from service activities [1],[2], [3]. This trend, referred to as the 'servitization' [4] or 'servicisation' of manufacturing [5], [6], [7], has seen manufacturers shift their focus from tangible products towards the provision of various products and service combinations, sometimes delivered over an extended period of time as an 'integrated solution'[8] or 'product-service system' [5],[9]. Several manufacturers now derive the majority of their revenue from service activities [10], and a study of eighty major international manufacturers revealed service revenues accounted for an average $25 \%$ of business, and $46 \%$ of profits [11]. Neely suggests that around one third of firms officially classified as 'manufacturers' can actually be more accurately described as 'combined manufacturing and service firms' given the significance of their service operations [12]. Yet for many organizations the servitization journey can be a difficult one, and may fail to generate anticipated financial returns, a phenomenon Gebauer et.al label the 'service paradox' [1].

Most of the existing research into servitization and product-service strategies is written from marketing, operations management and engineering perspectives, and highlights a range of strategic, technological and organizational implications [9]. While cultural and human resource management (HRM) aspects are frequently alluded to [1],[2],[13],[14],[15],[16], few studies have expressly engaged with these issues, or provided detailed empirical evidence of the HR implications of this business phenomenon. Given that HRM is a critical success factor in promoting 
both product and service quality [17], this presents a significant limitation to our current understanding and an inhibitor to the enactment of the business model in practice. The purpose of this article, therefore, is to assess the extent to which employees have the ability, motivation and opportunity to successfully support organizational product-service (PS) strategies. We contribute to the ongoing and multi-disciplinary product-service debate in three ways. Firstly, we explicitly focus upon the people management implications of PS strategies from an HR perspective. Secondly, we present empirical insights from two case studies of leading global engineering firms widely considered to be advanced in their adoption of productservice (PS) business strategies, and which have significantly increased the proportion of revenue generated from services over the last two decades. Thirdly, we suggest a need to reconceptualise the service paradox by going beyond a narrow focus on increased financial returns, and revealing how - even where service strategies are profitable - firms may still encounter significant challenges and struggle to fully exploit their service strategies.

The remainder of the paper is structured as follows. Firstly, we present a brief review of the product-service phenomenon, before outlining the analytical framework employed. After outlining the research methods, we present two case studies of international engineering organizations espousing the product-service vision. The article concludes with an analysis of the case findings, and reveals how HR issues represent a crucial missing link in the theory and practice of the product-service agenda and discourse. 


\section{THE TRANSITION FROM PRODUCTS TO SERVICES}

The growth of services has become one of the most notable trends in recent years, and has been reflected in the changing structure of many advanced national economies where services now account for the majority of national output [12]. At a firm level, the boundaries between product and service providers have also become increasingly blurred especially in industrial and business-to-business markets. In many engineering organizations for example, historically the focus has been upon the manufacture of tangible goods. Additional services may have been provided but in an ad hoc way; and in some cases aftercare and support might have been offered on a reactive basis, sometimes even for free. However, the importance and status of service activity in manufacturing has been increasing, as a potential differentiator and means to increase the value for customers in a crowded and competitive marketplace [9],[10].

The most advanced manifestation of this is the development of product-service solutions, where clients pay for an agreed 'outcome' such as the 'availability' of an asset, or a performative outcome with an upfront risk-reward performance contract. The emphasis therefore shifts from 'sale of product' to 'sale of use' [18]. Examples of this include IBM shifting from being sellers of IT hardware and software provision to offering complete data and information consulting 'solutions' [19]. In Europe, Alstom is said to be a provider of 'transport solutions' rather than merely a manufacturer of rolling stock [19], [20].

The potential opportunities associated with offering PS are often contrasted with the more limited and reactive maintenance product support most manufacturing organizations have always provided [10], [21], [22], [23]. The PS business strategy 
is based upon the proposition that for manufacturers the focus upon tangible goods alone may now be insufficient as a future source of sustainable competitive advantage [2], [24], [25], [26]. It follows that services should now be viewed as a strategic opportunity for manufacturers rather than a costly and low-status 'necessary evil' [27], [28].

For clients, the putative benefits of procuring PS include less unpredictability and risk, access to the original manufacturer's technical expertise, and an ability to outsource activities and focus upon their core business [2]. It allows a financial service organization, for example, to outsource their IT requirements to a specialist third party provider as a bundle of work, or an automotive manufacturer to outsource all plant maintenance to the provider of an 'engineering services solution'. It therefore supports business trends towards outsourcing, a focus on core competencies, and the development of flexible firms [29]. For solutions providers, the benefits are claimed to include more stable income streams, higher profit margins, differentiation, ability to develop long-term relationships with customers, and to exploit the technical knowledge and knowhow they possess [1],[18],[24],[29]. Crucially, the provision of high-value product and service combinations can also be viewed as offering much-needed insulation to manufacturers in developed economies from low-cost competition from emerging economies [12], as well as cushioning from economic cycles to which clients' capital expenditure is inextricably linked [2].

\section{The service paradox}

Despite the espoused benefits of increasing service activity, a recurring theme is how difficult it is for organizations to implement a financially successful PS strategy, 
and various studies have highlighted the significant challenges often encountered [1], [18], [24], [31], [38], [39], [40]. As Gebauer et al. conclude:

"Most [manufacturing] companies find it extremely difficult to exploit successfully the financial potential of an extended service business. Most...increase their service offerings and incur higher costs, but this does not result in correspondingly higher returns...We term this the 'service paradox' in manufacturing companies" [1].

Our current understanding of what underpins the service paradox remains limited. Research has tended to categorise different service strategies[10], mapped a 'transition' form products to services [1], [2], [7], [15], [24], and consultancies in particular have provided various guidelines and 'best practices' to support PS strategies [11], [13], [24], [35], [36], [37]. Organizations are urged to reconsider the nature of their organizational structures and processes [1], [10], [20], [30], [31], [32], customer relationship management [29],[33], and service design [34].

Most studies recognise that the successful PS strategies depend partly upon effective people management but acknowledge that this may in practice prove challenging [14], [15[, [41], [42]. References are frequently made to a need to facilitate 'cultural' and 'attitudinal' changes required to make a transition from product manufacturer to product-service provider [3], [10], [14], [24], [34], [43]. Indeed, it is suggested that old organizational cultures predicated upon products may actually be an impediment to PS provision, and that "changing the mindsets of thousands of employees who have grown up with a narrow vision of products or services is perhaps the biggest barrier of all" [20]. Cultural values associated with manufacturing, such as efficiency and economies of scale, are said to be different to 
modern service values which emphasise flexibility, innovation and customisation [1], [41].

New organizational structures are suggested, normally involving the creation of a separate front-end service organization to minimise potential clashes between the embedded manufacturing and the new desired service-oriented cultures [13], [29], [42], [44]. Indeed, the literature suggests creating 'front-end' service organizations where distinctive attitudes, behaviours, skills, job roles, and incentives are said to be required [14], [15], [20], [43] requiring the development of talented front-end staff to fill new roles. Front-end employees should possess excellent relationship management, customer service, negotiation and technical skills [2], [13], but teams should also consist of a mix of new staff who can inject new ideas, as well as existing staff who are aware of the history and culture of the organization [2], [13]. New reward packages for service staff are said to be required which encourage nurturing long-term relationships with clients, with pay linked to individual and business goals, in a way which both promotes solutions-based working and encourages company-wide collaboration and co-operation [1], [2], [13], [29]. Other HR aspects mentioned include rotating assignments across business units to foster cooperation [13], and an emphasis on fluid working across boundaries rather than hierarchical lines of command often associated with manufacturing [2]. Change is said be underpinned by strong leadership in order to achieve buy-in and which ultimately may require the "removal" of employees who resist change [13]. More recently, research has investigated the implications of servitization for HR practitioners [45]. 
While such suggestions are intuitive, the empirical evidence and theoretical explanations regarding people management issues in organizations pursuing a servitization journey remains surprisingly thin. Developing our understanding of HR issues is essential, given that new business strategies and forms of work and organization demand new HRM policies and practices [46]

\section{Conceptual framework}

In order to improve our understanding of the HR dimension we employ a framework central to notions of strategic human resource management. The 'Ability, Motivation, Opportunity' (AMO) framework presented by Boxall and Purcell [46] is deployed as an analytical lens through which we can assess desired and actual individual employee performance (see also Appelbaum et.al [47]; Bailey, [48]). For Boxall and Purcell $(2008,5)$ HRM can be viewed as a set of activities aimed at building and aligning individual and organization performance. They propose that fundamentally organizations aim to attract, retain and develop 'motivated capability'. At the individual worker level, they propose that this can be thought of as a function of employee Ability + Motivation + Opportunity [46], [49]. In other words, individual employees perform best when (i) they have the ability to perform (ii) they have the motivation to perform and (iii) they have the opportunity to deploy their skills and abilities.

Ability refers to the knowledge, skills, attitudes and behaviours required to carry out a job, and is influenced by factors such as education, life and work experience, and personality traits. Effective recruitment, selection, training and performance management are related HR policies. Motivation refers to an individual's willingness to perform tasks and the level of effort they choose to exert. It is recognised that 
high or consistent levels of motivation are not necessarily automatic. Effective economic incentives and rewards are obvious HR tools in this regard, though these alone cannot guarantee desired behaviours. Career development, employment security, promotion opportunities as well as recognition are possible factors. Finally, from an HR perspective, opportunity typically relates to issues of job design, work environment, and participation in decisions and employee involvement. The AMO framework proposes that these three principles are mutually reinforcing and that managers need to influence these three mediating variables positively to 'unlock' high levels of employee performance. For this reason they are deemed to be at the heart of strategic human resource management [46].

\section{METHODS}

A case study approach was adopted in order to reveal how and why PS strategies play out in practice in particular organizational and sectoral contexts, as well to understand more about the meanings that actors associate with the notion of PS. A key aim was to capture the views of actors with responsibility for operationalising major organizational PS strategies. A further aim was to capture insights from the perspectives of those involved in both 'front-end' and 'back-end' activity. Thus the aims of this study lend themselves to an inductive, qualitative approach in order to reveal the details of the interpretations and perceptions held by respondents. Such issues would be difficult to address using quantitative indicators, which might reveal little about the process of enacting PS business strategies. As selection of cases is central to theory building from case study research [50], a degree of 'purposeful sampling' was employed. Given the aim of the research, two case organizations were selected in order to provide points of contrast and comparison, and in turn 
improve opportunities for analysis and theory building. The global organizations under study are widely cited in the current literature as exemplars of firms with successful and well-established worldwide 'PS' strategies, and are well known in their respective sectors as organizations which have been shifting from products to services. This is confirmed by a significant increase in their service revenues in the last two decades. By selecting two firms which had significantly increased service revenues, we were able to focus upon examining both the common and differentiating factors characterising the evolution of their ostensibly successful servitization journey.

The bulk of the data was gathered through interviews with a range of senior and operational managers in each organization, referred to as JetCo and EngCo. The overall aim was to compare management perceptions of the servitization journey in each organization, and the research involved ongoing engagement with both case study organizations over a three year period between 2006 and 2008. Three main questions guided our empirical investigation of people management issues:

1. To what extent do employees have the ability to support PS strategies?

2. To what extent are employees motivated to support PS strategies?

3. To what extent do employees have the opportunity to support PS strategies?

Interviews were semi-structured and typically lasted between 45 and 90 minutes in duration. At JetCo interviews were conducted across three organizational divisions with a total of 18 informants. A key part of the design was not to limit our interviews to HR specialists, but to obtain the views of a cross-section of other functional specialists with responsibility for enacting and developing aspects of the PS strategy. 
Job roles included the Director of Information Strategy, Head of Programme and Systems Engineering, Operations Centre Manager, and Business Development Manager. We also interviewed HR specialists of various levels of seniority, including the HR Director for Services, Organizational Development Director, and HR Business Partners for each division. At EngCo the 24 informants were drawn from two divisions, and job roles included Service Manager, Service Development Management, Business Development Manager and Vice President Customer Support. Again, several HR specialists were also interviewed including the Head of UK HR, and several divisional HR Business Partners and HR Officers. Potential respondents were identified in each organization in collaboration with the organizational gatekeeper, with the overarching aim of achieving a wide range of perspectives. There was also an element of snowballing with some respondents also identifying other suitable interviewees. Given the focus of the research on understanding managerial perceptions of overall servitization journey, respondents were limited to those in senior and operational management/supervisory roles. In order to address the overall aims, interview themes were twofold. Initial questions related to evolving business strategies, and in particular the characteristics, challenges, and opportunities of aftermarket services. Subsequent questions then focused more upon the people management implications and challenges of PS strategies, with questions devised to inform our interest in understanding people HR issues, and most notably employee ability, motivation and opportunity to perform. A key focus was upon understanding the extent to which employee attitudes and behaviours were supportive of product-service strategies. All interviews were recorded and transcribed verbatim. Transcripts were each studied by two team members and then coded, using the themes which formed an integral component of 
the interview schedule, as well as themes which evolved from the data. Particularly insightful or revealing transcripts or excerpts from transcripts were also identified and shared with other members of the team. NVivo software was used to aid qualitative analysis, and each transcript was coded and annotated with notes on relevant themes. Regular team meetings were held to compare researcher interpretation of the findings. Informants also provided various documents which provided a valuable source of triangulation, and also afforded the opportunity to establish a deeper contextual and historical understanding.

Given the three-year engagement with the organizations, findings were presented to senior managers in both organizations at various points. Typically this involved a written report followed by an interactive feedback session with the research team. These meetings were around two to three hours in duration, and afforded the opportunity for the research team to check interpretation, to clarify uncertainties and ambiguities, and to gain extremely valuable feedback on findings. As such, these sessions formed an integral component of the analytical and verification processes. The study also benefits from the opportunity for investigator triangulation [51], as data was collected and analysed by a team of multi-disciplinary team of researchers. Finally, it is important to note that the aim of the research was not necessarily to generate findings which are readily generalisable to other organizations, but to produce insights which contribute to the development of broader theory (analytical rather than theoretical generalisation) [50],[51]. 


\section{TWO CASE STUDIES OF GLOBAL ENGINEERING ORGANIZATIONS}

\section{Case descriptions}

EngCo is a leading multi-national power and automation technology company, with clients across the manufacturing, utilities, pharmaceuticals, and food and beverage sectors. The organization, which employs over 100,000 staff in 100 countries, was said by a commercial manager to be shifting their traditional focus as an international engineering manufacturing organization, and moving "up the value chain" to becoming a provider of "engineering and technology solutions". Service revenue now accounts for around $20 \%$ of total turnover. A key aspect of this strategy was a desire to provide comprehensive asset management services through the life of their products, as opposed to traditional reactive ad hoc maintenance provision. Delivering PS solutions at EngCo involves a 'risk-reward' 'Proactive Lifecycle Maintenance Programme' referred to here as (PLMP). In contrast to an ad hoc service contract, PLMP involves EngCo entering an ongoing partnership with a client organization to deliver a comprehensive programme of maintenance for their equipment, with agreed targets and objectives. Benefits for the client are said to include performance and efficiency improvements, increased reliability of equipment, reduced risk, access to EngCo expertise, cost control, the ability to focus upon their core business, and continuous improvement.

JetCo is a major global provider of power systems and service employing over 30,000 staff across 30 countries, and has reputation for manufacturing excellence. JetCo has a reputation for manufacturing excellence with major markets including the aerospace sector, and the growth of after-market services has been an aim of the organization since the 1990s, and service revenue now accounts for $50 \%$ total 
revenue. JetCo has always engaged in maintenance activity, but the 'new' service model was described in company literature as proactively engaging with customers to provide "comprehensive aftermarket support and engine availability through life", referred to as a Through Life Maintenance Plan (TLMP), is said to offer "comprehensive engine availability through life". This involves entering contracts where JetCo assumes some of the risk, with clients benefiting from associated with maintenance traditionally borne by clients. Again, clients were believed to benefit from reduced risk, access to the specialist maintenance knowledge of the Original Equipment Manufacturer (OEM), and an opportunity to rationalise their supply chains.

[TABLE 1 HERE]

The HR dimension: ability, motivation and opportunity

\section{$\underline{\text { Ability }}$}

Ability refers to the availability of knowledgeable and skilled employees [46]. At EngCo, it was recognised that one of the key demands of delivering PLMP contracts concerned finding employees with the required skills and knowledge, both in terms of person-job fit and person-organization fit, but this had proved challenging. With regard to person-job fit, PLMP arrangements involved the acquisition of most of the client's craft-level maintenance employees under the terms of TUPE', meaning EngCo could not selectively recruit front-line maintenance workers to support PLMP;

\footnotetext{
${ }^{1}$ Transfer of Undertakings (Protection of Employment) Regulations (TUPE). This provides an entitlement of employees to retain their existing contracts and protection from cuts in pay and conditions when a business transfer occurs.
} 
rather they typically inherited the client's existing maintenance staff. Where EngCo did recruit, skills shortages were problematic. As a Service Manager explained: “There doesn't seem to be the off the shelf skill set that we want. We can't just go out there and advertise for a 'Reliability Engineer'. What is that? Probably only one or two companies in the UK even use the terminology".

The emphasis was therefore upon developing people internally, and a recognition that EngCo must invest heavily in human resource development (HRD). At a corporate level training was available to support PLMP, yet the situation was described as a "chicken and egg”. As a PLMP Manager explained, "We simply don't have the critical mass to be able to take all these people on and then train them up as an overhead". Coaching and leadership were also believed to be required in order to change the culture of the maintenance function. Experienced EngCo employees familiar with PLMP would be deployed in key supervisory and managerial posts. As a service specialist explained, "we can add value by putting our own managers in with the aim of completely turning the maintenance function around". Yet EngCo had a shortage of experienced PLMP managers in the UK to fill these roles, meaning international assignments were often required but were difficult to arrange as the shortage of PLMP Managers was not unique to the UK.

At JetCo, there were also a variety of issues around the availability of employees with the required skills and knowledge. Internally, TLMP resulted in roles which required a combination of technical and service skills but attracting top technical talent service roles was challenging. Given service roles also required expert product and technical knowledge the emphasis was upon internal realignment rather than external recruitment. As a senior technical manager explained: "Our industry 
requires people to have an in-depth knowledge of the product so it's not necessarily about bringing new people in from outside to do these service roles. It's about repositioning people with that expertise to do those new roles, and then backfilling the technical roles with new people." However, some of the best technical experts were reluctant to move into a service role, while others were believed to lack the service skills for the new roles. As an HR manager stated: "We're looking for this weird hybrid of a technically brilliant person who's actually also very customer focused, and naturally builds good relationships. Do they exist? We're not quite sure how we develop them, or how we recruit them effectively especially for organizationto-organization service with this technical slant on it". Attracting employees from outside the organization was thought to provide a valuable injection of new ideas and assist with the desired cultural change, however, there were concerns regarding the extent to which JetCo recruitment strategies matched the distinctive needs of the evolving business, as well as the extent to which new ideas are readily accepted.

Accordingly, training and development was believed to be crucial. Traditionally training has emphasised product innovation and new product development, but the skills required in a TLMP environment were said to be different, For engineers, the current emphasis was on designing durable products which can be maintained and supported through life. New technical skills such as forecasting and scheduling also had to be developed. In addition to new technical skills, there was the need to develop service skills and the nature of service innovation and it was suggested this was where the business lacked experience, but a corporate service training programme focusing upon the attitudes and behaviours believed to be necessary in a more service-driven environment had been developed. 


\section{Motivation}

Motivation refers to the motivation of employees to behave as management expect [46]. At EngCo, pay and reward were believed to be important drivers of the desired culture of continuous improvement. However, as PLMP involved EngCo inheriting craft level employees previously employed by the client organization, there was a contractual and legal requirement that employees were transferred to the new employer under the same terms and conditions. Sometimes the client required EngCo to honour employment terms for the duration of the PLMP contract to avoid discrepancies should the contract be terminated early. Further issues concerned ensuring pay rates were competitive in order to attract and retain the right calibre of employees. Craft employees in particular were believed to be highly mobile in a search for higher pay, meaning EngCo required knowledge of the diverse geographical and craft labour markets. While pay linked to performance was believed to align with the ethos of PLMP, this only occurred at a managerial level, where pay would be linked to a range of Key Performance Indicators such as equipment availability and downtime. In short, management choice over pay and reward strategies were constrained by contextual factors. Additional complexity arose as several distinct groups of workers were involved in the delivery of the PLMP contracts, including ex-client employees, existing EngCo employees, newly hired employees, as well as agency staff on temporary contracts. This multiplicity of employment arrangements rendered a strategic or even equitable approach to terms and conditions highly problematic.

Reward and performance management practices were also believed to be important at JetCo. An HR Manager suggested a need to drive 'service behaviours' through 
the performance management process, and to shift towards rewarding more for displaying the desired "behaviours" rather than for "just delivering". This was contrasted with traditional manufacturing-oriented reward systems which were said to have emphasised achieving desired outcomes, with less focus upon how objectives were achieved. As an engineering team manager commented: "If you're wanting to improve service, and to build more of a service culture, then you need to have the behaviours that contribute to that built into the performance management system. There needs to be a much bigger emphasis on how things are achieved, not just achieving them. Historically, so long as you hit your target or deadline it was fine". In seeking to engender a customer orientation within the business new mechanisms were being developed to reward employees exhibiting desired behaviours, such as engaging in proactive actions to avert problems rather than "firefighting" or a "last minute crisis orientation". It was suggested that in the future, the organization would have to take account of customer views of performance. While it was recognised that reward and appraisal systems had to be reviewed in order to evaluate the extent to which they support the behaviours which underpin effective PLMP delivery, in practice there was lack of clarity around what this should look like, and managers felt constrained by well-established union management agreements which limited management choice in terms of their ability to develop bespoke reward packages for different groups.

\section{Opportunity}

Opportunity refers to the opportunity for employees to deploy their skills and abilities [46]. At EngCo, a high level of communication at all levels was believed to be essential in making a successful transition to a PLMP contract and ethos. New ways 
of working were thought to be required to deliver PLMP, and it was suggested that EngCo's position as an 'outsider' meant they could identify ways to improve maintenance and operational effectiveness. However, this also required changes to working time and shift systems, which are often based on historical or industry norms. Moreover, in order to identify potential opportunities to improve processes and identify efficiencies, EngCo had to capture valuable employee knowledge and suggestions. The desired level of employee involvement was said to be quite different to a more to-down approach associated with more traditional reactive maintenance operations. As a team manager explained, rather than viewing the maintenance function as a "necessary evil and a cost to be cut", there was a clear emphasis upon equipping employees with the relevant skills and opportunities to adopt a more proactive role and a fostering a more empowering style of management. However, there were also concerns among some employees regarding the implications of the changes, and in particular diverse working arrangements meant that the workforce remained deeply fragmented, which in turn acted as a barrier to participation and teamworking. As a senior PLMP business development manager explained: "It's really difficult to control these guys, very difficult indeed, because they are not a team. They all have different bosses, they all report to different organizations, and with agency staff, if they have the opportunity to get permanent employment somewhere else they're gone." This fragmentation and instability was believed to present a serious challenge to effective PLMP delivery.

In terms of opportunity at JetCo, PS was believed to require a greater degree of inter-functional co-operation, and greater employee awareness of the 'big picture'. As a service HR partner explained, "We're asking employees to look through the 
timeline of the product and also out into the wider organization rather than just thinking in their own little narrow band". PS was said to require more efficient relationships, between both internally between employees, and externally with clients. However, internal relationships were identified as being problematic, and in particular a palpable divide between "the product world" and "the service world". Resolving these internal tensions was seen to lie at the heart of embedding the PS culture throughout the organization to support the strategy. One example of this was the creation of a 24 hour operation centre providing customers' with a single point of contact with the organization, staffed by employees in a variety of customer service and specialist engineering roles able to provide clients with a more immediate response. Several employees had been seconded to work within the clients business to get a richer view of the airline environment and an understanding how they work. In this way, JetCo had begun to propagate a "service ethos" across the organization. Efforts had also been made to create more fluid career paths internally, especially between the product and service parts of the organization, in order to foster a broader understanding of the organization among employees.

\section{[TABLE 2 HERE]}

\section{DISCUSSION}

Our key aim was to enhance our understanding of the human resource implications of PS, and we used the AMO framework as a lens for this purpose. The following sections present the theoretical, managerial and research implications of our enquiry. 
Firstly, existing research highlights a need for organizations pursuing PS to build a talented cadre of customer-facing personnel, possessing both high-level technical and relationship-management capabilities. It is suggested that this will involve recruiting new staff, as well as the training, development, and upskilling of existing staff [2], [13]. We examined such issues under the category of 'Ability'. Reflecting the recommendations made in the literature, both organizations were seeking to develop excellent front-end service personnel, as well as a cadre of employees possessing a combination of expert product and technical knowledge, combined with various 'attitudes and behaviours' they associated with excellent service delivery [16], [20], [42].

However, in practice various contextual factors constrained management choice in this regard. At EngCo legal regulations regarding the acquisition of employees from clients meant managers did not have a free choice regarding resourcing strategy. Labour market shortages made senior leadership and craft-level roles difficult to fill, and a lack of clarity as to the competencies that workers should possess presented a further challenge. Somewhat paradoxically, investment in training and development was believed to be essential in supporting PS, but the relatively small scale of the PS operations resulted in a very conservative attitude to investing in new staff or costly development programmes. At JetCo many technical specialists were reluctant to move into more service-oriented roles, while many others were not believed to possess the desired blend of technical knowledge and service orientation. Indeed, identifying individuals with the desired blend of technical expertise and interpersonal competencies had proved difficult, and were not available in the external labour market. Attracting new recruits to bring fresh ideas into the business as part of the 
desired organizational transformation was supported in principle, but again it was noted that new entrants find they quickly have to "conform" to embedded organizational norms "in order to be taken seriously". Recruitment strategies and development opportunities were also thought to reinforce the status quo, as they had not been sufficiently reconfigured to support the evolving PS strategy as opposed to those which supported a traditional engineering manufacturer.

Secondly, existing studies also acknowledge that employee motivation is key to the delivery of PS and makes suggestions regarding the design of appropriate reward and incentive programmes which are aligned with PS business objectives [1], [2], [15], [29], [48]. We examined issues of 'Motivation' in each case organization, and performance and reward issues were identified as one of the enablers of PS. Again, management choice was again constrained by a variety of contextual factors. At EngCo terms and conditions were set under UK TUPE legislation meaning they could not alter pay after employees were acquired and thus limiting the ability to design a bespoke reward system. The possibility of transferring employees back to the client should the PLMP agreement be terminated reflected the tentative nature of some of these ostensibly long-term 'through-life' contracts in the early stages. Uncertainty and a desire to ensure a degree of labour flexibility also had consequences in terms of limited job security for some workers, and it was recognised that this was did not support a PLMP strategy predicated upon continuous improvement, and long term customer relationships [15], [31]. Rather, the approach to reward was driven more by legalistic compliance, manufacturing industry norms, and short-term business pragmatism, rather than strategic attempts 
to drive and influence behavioural change in support of their PS offering in the long term.

At JetCo, aligning reward strategies was again recognised to be a key component of a PS strategy, although at the time of the research, developments in this area were also in their infancy. It was recognised that to support PLMP the reward and performance management process ideally needed to be modified to put more emphasis on issues of process, i.e. how outcomes were achieved, as opposed to merely whether outcomes were achieved or not. It was suggested that such approaches were taking shape in the service organization, but that reward systems in the product organization remained rooted in a more traditional manufacturing paradigm developed and established agreements with the recognised trade unions. As a driver of behaviour this was thought to be a problem, and illustrates that PS delivery has important HR implications outwith the front-end service units. Indeed, there was a perceived need for an organization-wide review of reward to encourage collaborative working across and between teams and business units, and to ensure business targets do not pull employee behaviour in unintended directions to the detriment of service outcomes. Though the PS literature stresses the need to develop reward strategies which incentivise good service [15], [16], there was limited evidence to suggest this has been implemented in practice, and there was a lack of clarity around what this might look like. Consequently, it is feasible that the existing reward systems were actually reinforcing many of the manufacturing-oriented behaviours management were so eager to change [52].

Thirdly, existing research notes the importance of supportive structures and processes, as we examined these under the category of 'Opportunity'. In terms of 
the extent to which employees have the opportunity to deploy their skills existing research stresses the need for new arrangements characterised by high levels of communication, greater empowerment, joint working across departmental boundaries and inter-functional dependency [2], [30], [33]. Supportive organizational structures and processes around the delivery of PS more generally are also said to be essential [1]. Again, this broadly reflected the views of respondents at both JetCo and EngCo. At EngCo, the emphasis was upon fostering improved collaborative working between the EngCo maintenance teams working on clients sites, the clients own employees, as well as employees on an array of different contracts. Employee support for the new ways of working was certainly not automatic, and complicated by sometimes divergent interests of the different groups involved. At JetCo the emphasis was upon the need to galvanise the organization around the PS vision and foster more extensive inter-functional co-operation, as PS was believed to require the support of both product and service parts of the business. In both cases, despite a recognition that PS required high levels of intraand inter-organizational collaboration and employee involvement, in practice this was believed to be hampered by the fragmented nature of the workforce. Furthermore, PS constituted only one of many different concurrent strategic business priorities characteristic of large complex international organizations.

\section{CONCLUSION}

We set out to shed additional light the HR issues associated with organizational trends towards product-service agenda by investigation two financially successful service strategies. Existing research has typically focused upon creating a new service unit with distinctive HR practices more attuned to a service environment, but 
little is said about the implications for - or relationship with - the rest of the organization. Developing an effective customer facing service organization is unlikely to have much impact without the support and integration of the wider organization around the PS strategy to create a more integrated service system. There is also a lack of consistency regarding which practices should be adopted and whom they should be applied to [53], yet a pick-and-mix approach is unlikely to have the desired effect [54], and may indeed have little impact if individual policies and practices are pursued in isolation [46], [55].

Theoretical implications By employing the Ability, Motivation, Opportunity (AMO) framework as an analytical lens [46], our research reveals how most management emphasis has been placed upon developing the ability of employees to deliver PS. Managers had some idea of the skills and behaviours they believed were associated with PS delivery, and stressed the need for sophisticated recruitment and selection as well as extensive training and development. Regarding motivation, there was recognition that PS needed to reward employees across the organization in terms of the way they work and the behaviours they exhibit, as well as for the outputs and targets achieved. Motivating employees in each organization to behave in a way which supports PS had proved challenging and neither organization had yet fully reconfigured their reward and performance management systems to promote employee engagement with the PS agenda. This was due to both contextual constraints on decision making as well as a lack of clarity of what such a system should look like. For many managers, the move towards product-service had meant entering unchartered territory in HR terms. Furthermore, providing the opportunity to deliver PS was hindered by various non-HR issues, including organizational 
practices, processes and routines which often reinforced the status quo and acted as a barrier to attitudinal and behavioural change. These included a lack of conducive supply chain, logistics, operations management and information systems, as well as the less tangible issues of 'social architecture' [56]. Increasing levels of empowerment, employee involvement and teamworking were believed to be essential, but difficult to implement in practice. HRM practices remained geared around supporting productive industrial manufacturing. Consequently, they retained an internal focus upon easy to measure outputs and behaviours, with little emphasis on crucial but less tangible attitudes and behaviours which can have a profound effect on service quality [57], [58].

Our study thus makes several contributions. Empirically, by examining two cases of servitization popularly considered to be successful, we reveal some of the complex realities of operationalising product service strategies in practice, and highlights the importance of a more holistic and context-sensitive approach to developing coherent HR practices and supporting organizational processes in pursuit of PS, given their mutually reinforcing nature [46]. In theoretical terms, two implications of our research are worth highlighting. Firstly, our research questions the typically acontextual recommendations of 'best practice' HRM made in the HR literature, and consequently cast doubt upon the 'best practice for PS' recommendations made in the PS literature. We highlight the need for a more in-depth and contingent analysis of the people management implications in organizations pursuing PS strategies. Secondly, we propose a need to broaden the narrow financial conceptualisation of a 'service paradox' as defined by Gebauer et.al [1]. Even where firms have managed to generate healthy financial returns and increased the proportion of their service 
revenues, seemingly intractable human resource and organizational challenges might still be encountered. Without overcoming these challenges, firms might be unable to fully exploit the potential of their servitization strategies as a potential opportunity for sustained competitive advantage and differentiation.

\section{Implications for research and practice}

Several implications can be drawn from the study for both research and practice. In terms of research, the study calls into question the underlying assumptions in the normative literature which implies that organizational change can facilitated relatively unproblematically, and reveals how in practice even successful organizations are likely to encounter various challenges in terms of identifying, devising and implementing supporting HR practices. We also question the implicit assumption that management can reconfigure organizations as they wish, and can embed new ways of behaving and working without any major hurdles. Management do not always have a free hand in their design of practices but operate in a particular national, institutional, sectoral and organizational context. We also highlight the need to consider whether HR practices (in terms of $\mathrm{AMO}$ ) as well as wider business practices are mutually supporting or contradictory, and reveal how achieving alignment is far from straightforward. Product-service strategies formed just one strand of a complex web of organizational strategies and management priorities, and much will depend upon the coherence of policies, and how they are actually implemented in practice and 'brought to life' [46], [49], [59], [60]. The study also confirms that the HR challenges of PS are not confined to the 'Service Department' and suggests that the main challenge is devising an HR/service system which meshes the strengths of the product and service organizations together to deliver a 
true high-value PS solution [41]. This raises research questions regarding supportive $H R$ architecture [53]. Ultimately, it is the unique combination or HR practices and organizational processes which is most difficult to imitate [61]. In short, there is a need to develop mainstream HR theory in a way which can inform practice in organizations attempting to mesh hitherto distinctive manufacturing and service paradigms.

Given that one third of international manufacturers are now pursuing a PS business strategy [12], including many of the worlds most high profile firms, this raises important issues for management practice. For management and practitioners, it is the creation of a supportive an integrated service system which is likely to be key to achieving competitive advantage in the 'solutions' marketplace [58]. The engagement of HR professionals within the PS strategic agenda is likely to be key, yet the input of HR specialists and theorists are largely absent from the debate, which remains focused upon marketing and operations management implications. It is important to think through the implications of PS for HRM policy and practice, otherwise a misalignment may occur, ultimately lead to negative customer experience. This might involve, for example, increased emphasis upon external customer evaluations of the effectiveness of HRM, evaluations of performance from internal customers. HR practitioners must adopt a more strategic role, engaging their expertise upfront to ensure HRM considerations are accounted for in the design of service offerings. As long as HR issues remains excluded, people management issues will continue to represent a missing link in both the theory and practice of the product-service business phenomenon.

\section{Limitations and future research}


In this study we have examined management perceptions of the product-service journey, and their perceptions of the extent to which employees are able to support product-service strategies in terms of their ability, motivation and opportunity. Future research could benefit from examining such issues from the perspective of employees. We have also focused upon understanding the development of 'motivated capability' by examining individual workers. However, we recognise in reality that mobilising capable and motivated individuals is only one aspect, and further research could useful explore in more depth the social and collective dynamics which also influence employee performance, as well as the relevant bundles and systems of HR practices and policies which might help organizations overcome the service paradox.

\section{References}

[1] H. Gebauer, E. Fleisch, E. and T. Freidli, Overcoming the service paradox in manufacturing companies, European Management Journal, vol 23(1) pp.14-26, 2005.

[2] A. Davies, T. Brady, P. Tang, M. Hobday, H. Rush, and D. Gann, Delivering integrated solutions, November, SPRU, 2003.

[3] M. Sawhney, Creating growth with services, Sloan Management Review, vol 45(2), pp3443, 2004.

[4] A. Vandermerwe, S. and J. Rada Servitization of business: adding value by adding service, European Management Journal, vol 6, pp.315-324, 1998.

[5] T. Baines, and H. Lightfoot, Towards an operations strategy for the infusion of productcentric services into manufacturing in H. Demirkan, J. Spohrer, J.and V. Krishna, Service Science: Research and Innovations in the Service Economy, Springer US, pp89-111, 2011.

[6] J. Quinn, T. Doorley, P. Paquette, Beyond products: service based strategy, Harvard Business Review, vol 68(2) pp58-60, 1990.

[7] B. Van Looy, P. Gemmel, S. Desmet, R. van Deerdonck, S. Seernels, Dealing with productivity and service quality indicators in a service environment: some field experiences, International Journal of Service Industry Management, vol 9(4), pp359-376, 1998. 
[8] S. Brax, and K. Johnson, Developing integrated solutions offerings for remote diagnostics, International Journal of Operations and Production Management, vol 29(5), pp539-560, 2009.

[9] T. Baines, H. Lightfoot, O. Benedettini, D. Whitney, D. and J. Kay The adoption of servitisation strategies by UK manufacturers, Journal of Engineering Manufacture, Part B, vol 224(5), pp815-829, 2009.

[10] V. Mathieu, Product services: from a service supporting the product to a service supporting the client, Journal of Business and Industrial Marketing, vol 16(1) pp39-58, 2001.

[11] Deloitte, The service revolution in global manufacturing organizations, Deloitte Research, 2006.

[12] A. Neely, The servitisation of global manufacturing: an analysis of global trends, $14^{\text {th }}$ European Operations Management Conference, Ankara, Turkey, 2007.

[13] N.W. Foote, J. Galbraith, O. Hope, O. and D. Miller, Making solutions the answer, McKinsey Quarterly, vol (3), pp84-93, 2001.

[14] C. Homburg, N. Fassenach, N and C. Guenther, The role of soft factors in implementing a service oriented strategy, Journal of Business to Business Marketing, vol 10(2) pp23-51, 2003.

[15] W. Neu, and S. Brown, S. Forming successful business-to-business services in goods dominant firms, Journal of Service Research, vol 8(1), pp3-17, 2005.

[16] W. Neu and S. Brown, Manufacturers forming successful complex services, International Journal of Service Industry Management, vol 19(2), pp232-251, 2008.

[17] F. Horwtiz, and M. Neville, Organization design for service excellence: a review of the literature, Human Resource Management, vol 35(4), pp471-492, 1996.

[18] T. Baines, H. Lightfoot, S. Evans, A. Neely, R. Greenough, J. Peppard, R. Roy, E. Shehab, A. Braganza, A. Tiwari, J. Alcock, J. Angus, M. Basti, A. Cousens, P. Irving, M. Johnson, J. Kingston, H. Lockett, V. Martinez, P. Michele, D. Tranfield, J. Walton, J. and H. Wilson, State of the art in product-service systems, Journal of Engineering Manufacture Part $B$, vol 221(10), pp1543-1551, 2007.

[19] B. Auguste, E. Harmon and V. Pandit, The right strategy for service companies, McKinsey Quarterly vol (1), pp41-50, 2006.

[20] A. Davies, T. Brady M. and Hobday, Charting a path towards integrated solutions, MIT Sloan Management Review, 47(3), pp38-49, 2006.

[21] M.A. Cohen, N. Agrawal, \& V. Agrawal, Winning in the Aftermarket. Harvard business review, vol 84(5), pp129, 2006.

[22] R. Frambach, I Weslips, and A. Gundlach, Proactive product-service strategies, Industrial Marketing Management, vol 26(4), pp341-52, 1997.

[23] K. Goffin and C. New, Customer support and new product development: an exploratory study, International Journal of Operations and Production Management, vol 21(3), pp275301, 2001.

[24] R. Oliva, and R. Kallenberg, Managing the transition from products to services, International Journal of Service Industry Management, vol 14(2), pp160-172, 2003. 
[25] A. Slywotzsky, Value Migration, Harvard Business School Press, Boston, MA, 1996.

[26] A. Slywotzky, and D.J. Morrison, The profit zone, Chichester, John Wiley and Sons, 1997.

[27] M. Lele, After-sales service: necessary evil or strategic opportunity, Managing Service Quality, vol 7(3), pp141-145, 1997.

[28] R. Wise, and P. Baumgartner, 'Go Downstream: The New Profit Imperative in Manufacturing “', Harvard Business Review, Sept/Oct, pp133-141, 1999.

[29] C. Windahl, P. Andersson, C Berggren, and C. Nehler, Manufacturing firms and integrated solutions: characteristics and implications, European Journal of Innovation Management, vol 7(3), pp218-228, 2004.

[30] J. Galbraith, Organizing to deliver solutions, Organizational Dynamics, vol 31(2), pp194207, 2002.

[31] H. Gebauer, B. Edvardsson, \& M. Bjurko, The impact of service orientation in corporate culture on business performance in manufacturing companies. Journal of Service Management, vol 21(1), pp237-259, 2010.

[32] H. Gebauer, M. Paiola, B. Edvardsson, "Service business development in small and medium capital goods manufacturing companies", Managing Service Quality, Vol. 20 Iss: 2, pp123-139, 2010.

[33] D. Miller, Q. Hope, R. Eisenstat, N. Foote, and J. Galbraith, The problem of solutions, Business Horizons, vol 45(2), pp3-12, 2002.

[34] N. Slack, Patterns of servitisation, Institute for Manufacturing, Cambridge, 2005.

[35] Booz Allen Hamilton, The truth about customer solutions, Viewpoint, 1999.

[36] Booz Allen Hamilton, Customer solutions: building a strategically aligned model, Insights, 2001.

[37] McKinsey, Solutions selling: is the pain worth the gain? McKinsey and Company, 2003.

[38] S. Brax 'A manufacturer becoming service provider-challenges and a paradox', Managing Service Quality, vol 15 (2), pp142-155, 2005.

[39] F. Ceci, and A. Masini, Balancing specialised and generic capabilities in the provision of integrated solutions, Industrial and Corporate Change, vol20(1), pp1-41, 2011.

[40] A. Davies, Moving base into high value integrated solutions, Industrial and Corporate Change, vol 13(5), pp727-56, 2004.

[41] D. Bowen, C. Siehl, and B. Schneider, A framework for analysing customer service orientations in manufacturing, Academy of Management Review, vol 14(1), pp75-95, 1989.

[42] H. Gebauer, C. Bravos-Sanchez, E. and Fleisch, Service strategies in product manufacturing companies, Business Strategy Series, vol 9(1), pp12-20, 2008.

[43] M. Hobday, A. Prencipe, and A. Davies 'Introduction' , in A. Prencipe, A. Davies and T. M. Hobday, The Business of Systems Integration, Oxford, Oxford University Press, 2003. 
[44] H. Gebauer, T. Freidli, and E. Fleisch, Success factors for achieving high service revenues in manufacturing companies, Benchmark, vol 13(3) pp374-386, 2006.

[45] J.Z. Raja, S..D. Green, and R. Leiringer. "Concurrent and disconnected change programmes: strategies in support of servitization and the implementation of business partnering." Human Resource Management Journal vol 20 (3), pp258-276, 2010.

[46] P. Boxall, and J. Purcell, Strategy and human resource management. New York: Palgrave Macmillan, 2008.

[47] E. Appelbaum, T. Bailey, P. Berg Manufacturing advantage, Ithaca, NY, ILR Press, 2000.

[48] T. Bailey "Organizational innovation in the apparel industry", Industrial Relations, vol. 32(1), pp30-48, 1993.

[49] J. Purcell, N. Kinnie, and S. Hutchinson, Understanding the people and performance link, CIPD, London, 2003.

[50] K.M. Eisenhardt, "Building theories from case study research", Academy of Management Review, vol. 14(.4), pp.532-50, 1989.

[51] N.K. Denzin, The research act in sociology. London: Butterworths, 1971.

[52] S. Kerr, On the folly of rewarding A while hoping for B, Academy of Management Journal vol (18), pp769-783, 1975.

[53] D. Lepak, and S. Snell, The strategic management of human capital, Academy of Management Review, vol 24(1), pp1-18, 1999.

[54] B. Becker, M. Huselid, P. Pickus, and M. Spratt, HR as a Source of Shareholder Value: Research and Recommendations, Human Resource Management, vol 36(1), pp39-47, 1997.

[55] J.P. Macduffie, 'Human Resource Bundles and Manufacturing Performance: Organizational Logic and Flexible Production Systems in the World Auto Industry', Industrial and Labor Relations Review, vol 48 (2), pp197-221, 1995.

[56] F. Muller, Human resources as strategy assets, Journal of Management Studies, vol 33(6), pp757-85, 1996.

[57] B. Schneider, and D.E. Bowen, Personnel/Human Resource Management in the Service Sector in Rowland, K. and Ferris, G. Research in Personnel and Human Resources Management, JAI Press, Greenwich, CT, 1992.

[58] B. Schneider, HRM: A Service Perspective, International Journal of Service Industry Management, vol 5(1), pp64-76, 1994.

[59] L. Gratton, V. Hope-Hailey, P. Stiles, and C. Truss, 'Linking individual performance to business strategy: The people process model' Human Resource Management, vol 38(1) pp17-31, 1999.

[60] C. Truss, L. Gratton, V. Hope-Hailey, P. McGovern, and P. Styles, Soft and hard models of human resource management: a reappraisal, Journal of Management Studies, vol 34(1), pp53-73, 1997. 
[61] N. Kinnie, and J. Swart, 'Human Resource Management and Organizational Performance' in T. Redman and A. Wilkinson Contemporary Human Resource Management, London: FT Prentice Hall. (3rd ed), 2009.

TABLE 1: THE CASE STUDY ORGANIZATIONS

\begin{tabular}{|l|l|l|}
\hline & \multicolumn{1}{|c|}{ ENGCO } & \multicolumn{1}{|c|}{ JETCO } \\
\hline ORGANIZATION & $\begin{array}{l}\text { Power and automation products and } \\
\text { service }\end{array}$ & Power Systems and Service \\
\hline EMPLOYEES & 100,000 & 40,000 \\
\hline OPERATIONS & 100 countries & 40 countries \\
\hline SERVICE REVENUE & $20 \%$ total revenues & $50 \%$ total revenues \\
\hline PS OFFERING & $\begin{array}{l}\text { Proactive Lifecycle Maintenance } \\
\text { Programme (PLMP) }\end{array}$ & Through Life Maintenance Plan (TLMP) \\
\hline
\end{tabular}

TABLE 2: SUMMARY OF FINDINGS

\begin{tabular}{|c|c|c|}
\hline & ENGCO & JETCO \\
\hline ABILITY & $\begin{array}{l}\text { - Difficult to recruit new external employees } \\
\text { - Inheriting existing internal employees } \\
\text { - New job roles } \\
\text { - Cost of training prohibitive } \\
\text { - Suitable leaders scarce }\end{array}$ & $\begin{array}{l}\text { - Difficult to recruit new external } \\
\text { employees with required technical } \\
\text { knowledge } \\
\text { - Lack of interest in new service roles } \\
\text { among internal technical employees } \\
\text { - External recruitment focused upon } \\
\text { traditional business requirements } \\
\text { - Training and development focused } \\
\text { upon traditional business requirements }\end{array}$ \\
\hline MOTIVATION & $\begin{array}{l}\text { - Inheriting existing terms and conditions } \\
\text { - Various sets of terms and conditions } \\
\text { - Inability to introduce performance related } \\
\text { pay } \\
\text { - Competitive external labour market } \\
\text { - Employee concerns about development } \\
\text { and job security }\end{array}$ & $\begin{array}{l}\text { - Pay systems reward achieving product } \\
\text { oriented outcomes rather than service } \\
\text { oriented processes or employee } \\
\text { behaviours } \\
\text { - Traditional pay systems agreed with } \\
\text { unions } \\
\text { - Lack of a customer perspective on } \\
\text { (employee) performance }\end{array}$ \\
\hline OPPORTUNITY & $\begin{array}{l}\text { - Need to develop more participatory culture } \\
\text { - Constrained by employees expectations, } \\
\text { prior experience and industry norms } \\
\text { - Fragmented workforce } \\
\text { - Employee resistance }\end{array}$ & $\begin{array}{l}\text { - Traditional hierarchical structures and } \\
\text { division of labour } \\
\text { - Employees working in functional siloes } \\
\text { - Lack of cooperation between front-end } \\
\text { and back-end workers } \\
\text { - Slow processes }\end{array}$ \\
\hline
\end{tabular}

